\title{
ÍDOLOS Y SACRIFICIOS, UN GIRARD OLVIDADO
}

\author{
Agustín Moreno Fernández* \\ doi:10.11144/Javeriana.uph35-70.isgo
}

\section{RESUMEN}

Más allá de los clichés y de las simplificaciones que se aplican a la obra de René Girard, este trabajo reivindica el carácter crítico, independiente y complejo de su pensamiento. Un año después de su muerte y en el $25^{\circ}$ aniversario de su diálogo con teólogos de la liberación, volvemos nuestra atención a las memorias de este encuentro. Se trata de una muestra de la riqueza y de los matices de su pensamiento, ejemplificados en su perspectiva respecto a la Pasión, antes considerada como una narración antisacrificial y después revalorada como sacrificio, a pesar de lo cual Girard mantiene su propia denuncia de las lógicas del sacrificio, generadoras de víctimas de la pobreza, la exclusión y la indiferencia, de acuerdo con los teólogos del encuentro.

Palabras clave: René Girard; teoría mimética; teología de la liberación; sacrificio; cristianismo

* Universidad de Granada, Granada, España.

Correo electrónico: morenofdez@ugr.es

Para citar este artículo: Moreno Fernández, A. (2018). Ídolos y sacrificios, un Girard olvidado. Universitas Philosophica, 35(70), pp. 85-102. ISSN 0120-5323, ISSN en línea 2346-2426. doi:10.11144/Javeriana.uph35-70.isgo 


\title{
IDOLS AND SACRIFICES, A FORGOTTEN GIRARD
}

\author{
Agustín Moreno Fernández
}

\begin{abstract}
Beyond the stereotypes and simplifications of René Girard's work, this paper defends the critical, independent and complex character of his thought. One year after his death and in the 25th anniversary of his dialogue with several liberation theologians, we come back to the proceedings of the meeting. In this volume we can recognize the richness and nuances of Girard's thinking, exemplified in his perspective on the Christ's Passion, that he originally regarded as a non-sacrificial narrative, and then accepted as sacrificial, but keeping his own denunciation of the logic of sacrifice and agreeing with the theologians present at the meeting about its relation with the persistence of poverty, exclusion, and indifference.

Keywords: René Girard; mimetic theory; liberation theology; sacrifice; Christianity
\end{abstract}




\section{Introducción}

RENÉ GIRARD HA FALLECIDO y deja tras de sí un valioso legado que entra por méritos propios en la historia del pensamiento. Más allá de todo lo que esta herencia posibilite de cara al futuro, se impone también el estudio y el análisis de las fuentes. Incluso, el descubrimiento o el redescubrimiento de partes de su obra o de su biografía intelectual, olvidadas o ignoradas. Es el caso de su diálogo con teólogos de la liberación, del que se cumplieron 25 años en el 2015, año de la muerte del filósofo. Este artículo, junto con las efemérides señaladas, nos parece una excelente y oportuna ocasión para volver sobre este interesante y relevante episodio a través de la publicación a la que dio lugar. Nos servirá para reivindicar la complejidad de una obra que a veces corre el riesgo de ser simplificada o reapropiada conforme a la propia ideología, oscureciendo y desdibujando a su creador.

En primer lugar, ofrecemos una breve presentación del libro Sobre idolos y sacrificios. Después, defenderemos el carácter independiente y la diversidad de matices del pensamiento girardiano para situar en un contexto más amplio el interés de su diálogo con estos teólogos. Finalmente, presentamos una síntesis tanto de los contenidos del libro que nos resultan más interesantes acerca de Girard, así como del contenido de sus propias intervenciones transcritas y resumidas allí. Consideramos, de este modo, poder ofrecer una perspectiva raramente tenida en cuenta en los estudios girardianos y que hasta la fecha permanece ignorada en las publicaciones en español (como también en francés y en inglés, incluyendo libros y tesis doctorales), salvando honrosas excepciones ${ }^{1}$. Esta perspectiva está también ausente, al día de hoy, en las entradas que sobre Girard encontramos en las principales lenguas de la enciclopedia virtual Wikipedia, incluyendo las versiones en español y en portugués. ¿ Por qué? Dejamos esta pregunta en el aire.

1 Entre esas excepciones está Ruiz Lozano, 2005. Fue en la bibliografía de esta tesis doctoral en donde tuvimos noticia por vez primera de la obra de Girard que presentamos aquí. Otra excepción: De Castro Rocha, 2014. 
LA OBRA QUE LlEVA POR TÍTUlo Sobre idolos y sacrificios: René Girard con teólogos de la liberación (Assmann, 1991) es fruto del encuentro entre René Girard y un grupo de pensadores latinoamericanos, teólogos de la liberación, que tuvo lugar en São Paulo, del 25 al 29 de junio de 1990. El libro se compone de dos partes principales. A estas partes les anteceden los siguientes apartados: un índice de contenido, un sumario de temas específicos omitidos en la edición en español -que sí aparece en la edición original portuguesa-, un prólogo del editor Hugo Assmann y una breve biografía de René Girard.

En la primera parte encontramos una "visión general del encuentro", compuesta de los siguientes elementos: un listado detallado de participantes ${ }^{2}$ y sus adscripciones profesionales, académicas y confesionales (Assmann, 1991, pp. 17-18); unas notas de Hugo Assmann tituladas "Aspectos de la dinámica interna del diálogo entre René Girard y teólogos de la liberación” (Assmann, 1991, pp. 19-40); y la trascripción de fragmentos del diálogo. Las notas de Assmann incluyen el programa del encuentro, con un desglose de temas en epígrafes, distribuidos en mañanas y tardes, y a los que se asocian los diversos participantes. También, la descripción de la "dinámica interna" de cada día, donde se evoca el transcurso de las conversaciones, el ambiente, la disposición del grupo y las distintas intervenciones. La primera parte se completa con la transcripción de fragmentos del diálogo. Antes se ha advertido acerca del carácter condensado de partes del mismo ${ }^{3}$. La transcripción se distribuye en los días del encuentro y estos, a su vez, en epígrafes, bajo los cuales se hallan las intervenciones de los participantes o sus resúmenes (Assmann, 1991, pp. 41-93).

2 René Girard, Leonardo Boff, Julio de Santa Ana, Franz Hinkelammert, Jorge Pixley, Rubem Alves, Hugo Assmann, Carlos Palácio, Jung Mo Sung, Sebastião Armando Soares, Gilberto Gorgulho, James Alison, Benedito Ferraro, Luis Carlos Susin, Ely Eser Barreto César, Rui Josgrilberg, Paul Douglas Leslie, Norbert Arntz, Violaine de Santa Ana y Melsene Ludwig.

3 "Por obvias limitaciones editoriales, se optó por la inclusión de algunos pocos de los textos previamente escritos por los participantes y de una selección, extremadamente reducida y fragmentaria, de algunas intervenciones en el debate" (Assmann, 1991, p. 19). 
La segunda parte (Assmann, 1991, pp. 95-179), titulada "Contextualización básica”, se articula en torno a los textos de tres participantes: Hugo Assmann ("El pensamiento de René Girard despierta intereses diferenciados", pp. 97-117), Julio de Santa Anta ("Sacralizaciones y sacrificios en las prácticas humanas", pp. 119-147; "Algunas consideraciones sobre la mímesis sacrificial de los sujetos sociales modernos”, pp. 149-155), y Franz Hinkelammert ("Paradigmas y metamorfosis del sacrificio de vidas humanas", pp. 157-179). El libro concluye con una bibliografía en torno a la obra de René Girard (pp. 181-189).

\section{Un Girard olvidado, en contexto}

UnA De las Quejas de algunos de Quienes estudian la obra y el pensamiento de Girard, y no sin razón, hace referencia al hecho de que este queda mutilado, en tanto que se ignore o se oblitere uno de sus contenidos y tesis fundamentales: la irrupción histórica del cristianismo o, particularmente, de los Evangelios y su relato de la Pasión, como la narración antimítica por excelencia, que declara la inocencia de una víctima -al revés que los mitos, relatos de una comunidad de verdugos que culpabilizan primero y sacralizan después a la víctima - y sin la cual no podría entenderse el decurso de la historia: resquebrajamiento de las sociedades tradicionales y sacrificiales, y del Antiguo Régimen, secularización y cuestionamiento de la causalidad mágica en favor de la causalidad científica. Dicho de otra manera: se trata del desvelamiento del mecanismo del chivo expiatorio, de la lógica sacrificial, de la violencia y de los estereotipos de persecución, cuyo funcionamiento tampoco se entendería sin la formulación del deseo mimético, ambos aspectos (sociológico y psicológico) de una misma realidad interdividual humana de la que la teoría mimética pretende dar cuenta.

No obstante, también es cierto que la teoría mimética, al mismo tiempo que puede considerarse, y se considera en diferentes sentidos y vertientes, una teoría cristiana, no lo fue en sus inicios. Y no solamente es una teoría cristiana o que se alimenta exclusivamente de textos cristianos. Para percibir lo anterior, basta una mirada a las heteróclitas fuentes de Girard y a su ejemplificación del desvelamiento del mecanismo victimario en textos como los de los trágicos griegos o determinados textos hindúes, aunque siga reconociendo la superioridad de los textos evangélicos. 
En la trayectoria de René Girard pueden verse dos cuestiones principales en las que ha cambiado de criterio, ambas reconocidas por él. Una, con un menor desarrollo, se refiere a la concepción de un deseo heroico, espontáneo, capaz de ir más allá del mimetismo. La otra, que ha ocupado un mayor interés y ha llenado muchas páginas, consiste en la interpretación del cristianismo como religión no sacrificial. Ambas ideas quedan superadas por el pensador. Sobre la primera reconoce la influencia de Stendhal en Mentira romántica y verdad novelesca $a^{4}$ y también haber sido en esta obra víctima de un afán de complejidad para no caer en un aparente simplismo5. Sobre la segunda, Girard la interpreta como lo que quedaba en él de humanista y progresista en su interpretación del cristianismo (Girard, 2007, p. 1001, nota 1). Confiesa, además, haber sido influido por el mimetismo y contagiado de las opiniones y las críticas de su entorno sobre el cristianismo y la Iglesia (Girard, 1996, pp. 153-155).

No obstante, y asumiendo inevitables influencias, creemos poder afirmar que Girard ha sido un pensador independiente; no es posible encerrar a su obra ni a él en una órbita ideológica o política estrecha o cerrada, ni a la izquierda ni a la derecha, si bien cabe identificar la evolución de algunas posturas sobre algunos temas. Consideramos que, incluso si ha cambiado de punto de vista en la interpretación del cristianismo y de la Pasión como no sacrificiales, a la oposición dentro de una unidad simbólica entre "sacrificio del otro" (religiones arcaicas) y "sacrificio de sí" (religión cristiana), esto no invalida argumentos y críticas anteriores a los sistemas y prácticas para los que antes reservaba el adjetivo de "sacrificiales", ni tampoco posicionamientos como los que comparte con teólogos de la liberación.

No es baladí mencionar esto ya que, si bien es cierto que puede existir la tentación de mutilar la teoría mimética y a Girard obviando su teoría del cristianismo,

4 "En la época de Mentira romántica, verdad novelesca, bajo la influencia de Stendhal, yo oponía al deseo mimético un 'deseo espontáneo'. Pero he adoptado el hábito de reservar la palabra 'deseo' a esos apetitos, a esas necesidades, a esas apropiaciones diversas que penetra y rige el mimetismo" (Girard, 1996, p. 23).

5 "Según lo veo yo, una de las razones de la tendencia a eludir el concepto de imitación es que, amputado de su potencial intelectual, parece 'simplista', resulta un tanto decepcionante para el apetito actual de 'complejidad', que es por cierto muy mimético. Soy, por mi parte, plenamente consciente de esto, y de hecho mi primer libro ha sido víctima de esta manera de pensar" (Girard, 2000, p. 55). 
no es menos cierto que caben también otras tentaciones: ignorar su cambio de postura en el uso del término sacrificio (que antes negaba para la Pasión, concebida como antisacrificial), o ignorar también toda la potencia de su crítica a la lógica sacrificial de las religiones arcaicas que atraviesa la historia, afectando a la propia cristiandad, la Revolución francesa, los totalitarismos, los genocidios de distinto cuño y, también, al sistema capitalista actual. Cada cual podrá sentirse más o menos afín o cómodo; considerar como más o menos solventes determinados planteamientos y opiniones de René Girard con respecto a sus propias ideas y posiciones. Incluso, situarse, como ya sucedió tras Hegel, en una "izquierda" o en una "derecha" girardianas. O intentar prolongar a un Girard reducido y simplificado como "antimoderno", cuando, en realidad, al tiempo que es un crítico de la modernidad, sigue, en aspectos fundamentales, asido a ella, aunque nunca de manera ingenua. Tampoco puede decirse que Girard sea un antihumanista o un humanista, sin matizar qué entendemos por tales conceptos, aunque destaquen en sus publicaciones sus críticas al humanismo (Moreno Fernández, 2013).

A quienes puedan pretender aplanar o adueñarse de Girard conforme a la propia ideología, la honestidad intelectual debería animar a aclarar que es su visión sesgada de Girard y de la teoría mimética la que desarrollan en uno u otro sentido -no rindiéndoles la fidelidad que libremente cabe guardar o no-. Sea cual sea el caso, hay que subrayar que cualquier sesgo ideológico no se corresponde con la complejidad, la riqueza y la independencia del pensador, que no implica equidistancia o falta de posicionamiento frente a temas concretos, a veces de modo paradójico. Cabe mencionar, como ejemplos, la crítica de los "conceptos vacíos del humanismo" ${ }^{\text {; }}$ la deconstrucción radical del sujeto, concebido como ilusorio; la valoración de la noción de persona y la firma de un manifiesto internacional en contra del aborto (Moreno Fernández, 2014a, pp. 160-163); la crítica a la insuficiencia de las ideologías de izquierda y derecha (Girard, 2004, pp. 23-24); el cuestionamiento de la guerra de Irak (Girard, 2010, p. 11); la alerta contra el cambio climático (Girard, 2008, pp. 59-60), entre otros. También puede suceder, como el propio Girard expresa, que se le atribuyan determinados

6 “[... [L]o que no hay que hacer es pensar a golpe de grandes conceptos: los grandes conceptos vacíos del humanismo" (Girard, 2001, p. 91). 
presupuestos ideológicos de signo contrario a quien se los atribuye, sea por parte de gente de la derecha o de la izquierda (Assmann, 1991, p. 52).

En este amplio marco de interpretación y de asunción de los matices de las expresiones del pensamiento de Girard habría que destacar que ha quedado relegado su diálogo con teólogos de la liberación, cuando no olvidado o ignorado pasiva o activamente. Es oportuno sacarlo a relucir para continuar completando la riqueza del corpus de su obra. En particular, es relevante en lo que se refiere al cambio de postura más importante del pensador, a saber, su viraje hermenéutico en la interpretación del cristianismo, anteriormente concebido como religión no sacrificial.

Precisamente, en el rastreo de sus posiciones a este respecto no podemos olvidar el encuentro que tiene lugar en 1990 con teólogos de la liberación. Estos y Girard comparten su negación de la lectura sacrificial de la Biblia y de la Pasión -aunque Girard no ahonda en ella (Assmann, 1991: pp. 30-31, 35)-, que debe incluirse en un contexto más amplio de denuncia de los mecanismos sacrificiales. Aunque Girard haya cambiado después su interpretación de la Pasión, al dejar de considerarla como no-sacrificial, esto no quiere decir que deje de oponerse a los sacrificios de signo contrario al de Jesús o que deje de denunciarlos. Podemos aseverar que en lo sustancial mantendría su afinidad con estos teólogos. Ilustramos la coincidencia de Girard con teólogos de la liberación en palabras de H. Assmann (1991), primero ("Aspectos de la dinámica interna del diálogo entre René Girard y teólogos de la liberación”), y en palabras de Girard, después (“4.1. René Girard [29.VI. 1990-mañana]):

La explícita característica no-idolátrica y no-sacrificial de la teología de la liberación, enfatizada de manera creciente en los últimos quince años, era una de las convergencias más evidentes, pese a que -como el propio Girard insistió en reconocer- esa base común haya surgido de modo independiente. $[\ldots]$

Lo que nos une, de manera más evidente y más profunda, es ciertamente, y antes de todo, nuestro común rechazo al sacrificio de vidas humanas. Este rechazo de lo sacrificial -en la terminología peculiar de ustedes, del sacrificialismo- aparece, si entendí bien, junto con la teología de la liberación desde el inicio, ya en los años sesenta y setenta. Pude constatar esto en los textos, por 
ejemplo, en los de Leonardo [Boff] y otros. Eso significa que llegamos a este punto de coincidencia de forma independiente, cada cual por su camino propio. Es, pues, singularmente sólido esto que nos une: el rechazo del sacrificio. Por lo demás, yo no sabía que este rechazo del sacrificialismo era algo tan central en la teología de la liberación, y bajo una forma que le es muy peculiar y que me agrada mucho porque es, sobre todo, teológica (Assmann,1991, pp. 21,71$)^{7}$.

\section{El diálogo entre Girard y los teólogos de la liberación}

A CONTINUACIÓN OFRECEMOS, POR UNA PARTE, una síntesis de contenidos interesantes vertidos en el libro sobre René Girard. Por otra, un esbozo de los contenidos e ideas manifestados por Girard mismo en este encuentro a partir de las transcripciones de sus intervenciones.

Gracias a Hugo Assmann sabemos que hay más de 30 horas de grabación del diálogo entre Girard y los teólogos de la liberación (Assmann, 1991, p. 20) y cómo se llegó a organizar el encuentro. Fue el propio Assmann en 1989, en un simposio sobre Religión y violencia en Estados Unidos, patrocinado por la H. F. Guggenheim Foundation, quien le habló a Girard del reconocimiento de algunos teólogos de la liberación de las convergencias y conexiones entre su pensamiento y la teoría mimética, algo de lo que Girard no era aún consciente. La idea del encuentro tomó forma en esa ocasión y suscitó gran interés, con mayor número de candidatos invitados e interesados que de participantes finales, dada la limitación de recursos, que también habría determinado un marcado carácter brasileño del evento (Assmann, 1991, p. 21).

7 Girard continúa la cita viendo otro punto de afinidad que se colige del ya expuesto y que se inscribiría en la oposición girardiana a la disolución de la realidad en el lenguaje operada en ciertas filosofías: "[e]s esto lo que los diferencia también de esa especie de disolución total de la teología a la que asistimos en el mundo occidental. Porque los teólogos, en general, me parecen mucho más influidos que ustedes por aquello que se acostumbra a llamar 'desconstrucción', o sea, las tesis que afirman: solamente existen los lenguajes. Y es importante comprender que es precisamente su contacto con los pobres el que les impide, son ellos quienes les impedirán siempre, llegar a decir: nada existe más allá de los lenguajes. Este es un punto absolutamente fundamental” (“4.1. René Girard [29.VI. 1990-mañana]”. En: Assmann, 1991, p. 71). 
Assmann (1991) identifica el consenso entre Girard y los demás participantes en los siguientes términos:

[...] nuestro rechazo común a las lógicas sacrificiales que exigen sacrificios de vidas humanas; nuestra opción al lado de las víctimas; el hecho de estar inmersos en sistemas sacrificiales; y que era, probablemente, la puerta de entrada más obvia para un diálogo con René Girard (p. 23).

Tal consenso, sin embargo, tampoco le impide ver sus diferentes enfoques, algo que se hará patente también en los intercambios de pareceres y que dará lugar a recíprocos elogios, matizaciones y cuestionamientos, también críticos:

Para la teología de la liberación, el problema de las "víctimas" resultantes de los "mecanismos victimarios" no es una cuestión genérica. Se tiene el coraje de designar, con nombre concreto, quiénes son los sacrificados principales: los pobres, en cuanto empobrecidos, porque son excluidos de la lógica violenta del sistema. [...] En este énfasis en la contextualización histórica del sacrificialismo de parte de la teología de la liberación, aparece una cierta diferencia en relación a Girard, quien trabaja la cuestión más en un plano general y académico, privilegiando el análisis de los textos sobre el análisis de las realidades situacionales. Sin embargo, su análisis del deseo mimético tiene implicaciones fecundas para nuestro enfrentamiento con el contexto sacrificial en el cual estamos inmersos (p. 24).

Girard (citado en Assmann, 1991), que confesó estar impresionado por el acento político y social, también resultó franco:

La constante referencia a las víctimas, expresamente identificadas como el macabro resultado de la opresión, sobre todo económica, era evidentemente algo diferente de los ritos sacrificiales cuyo análisis predomina en sus libros. Habrá sido por eso que a cierta altura expresó: "la muerte..., nuestra especialidad de siempre”. [...] Lanzó, sin embargo, una astilla: las críticas políticas, con todo lo que ha sucedido en el Este europeo, ¿̨no están acaso fuertemente despotenciadas? (p. 27).

Encontramos más elogios, y también críticas, a Girard. Entre ellos destacan los que se refieren a las buenas actitudes del pensador, que despiertan admiración y entusiasmo en el coloquio. Assmann (1991) describe la participación de Girard como frecuente y con mucha desenvoltura y espontaneidad: 
Daba la impresión de que se sentía sumamente a gusto y hasta sorprendido con el nivel del debate. Hizo un planteamiento muy nítido sobre la defensa profética de los pobres y la denuncia de la idolatría. También resaltó la función de los mitos: cerrar la boca de las víctimas (p. 37).

Leonardo Boff alabó a Girard agradeciéndole su "santidad intelectual". Al contrario que otros intelectuales europeos y franceses, que en las discusiones tratarían de defenderse y autojustificarse, le parece que Girard tiene una actitud siempre abierta a la discusión y, más que de defensa de su teoría, de comprensión de fenómenos nuevos, lo que le recuerda a Boff a sus amigos Jean Ladrière y Paul Ricœur (Assmann, 1991, p. 84).

A Girard también le habría encantado, por ejemplo, la elaboración del concepto de "sabiduría" como confrontación y en ruptura con el círculo mimético, desarrollada por Gilberto Gorgulho (Assmann, 1991, p. 35). Bajo su punto de vista, la obra de Girard sería, más que un sistema, una sabiduría y Girard mismo, un sabio, al que habría que incluir como el cuarto maestro de la sospecha (Assmann, 1991, p. 87). Entre las críticas, la de Franz Hinkelammert, para quien Girard no ha destacado la justificación anti-sacrificial de la conquista de América, que habría justificado los sacrificios en las hogueras como sacrificios religiosos de los sacrificadores de indios, ya fueran aztecas, mayas o de otras culturas: "[e]n este punto sí me atrevo a criticar a René Girard, por el hecho de no enfocar y analizar este tipo de sacrificio tan importante para nuestra perspectiva, desde América Latina" (citado en Assmann, 1991, p. 50). Julio de Santa Ana lanza otra crítica al respecto de si la interpretación girardiana sirve realmente para todos los mitos (Assmann, 1991, p. 59). Encaja aquíla afirmación de Assmann (1991), según la cual "[e]l diálogo avanzaba, por lo tanto, entre todos sin ningún tipo de cobranzas dogmáticas, sin estrechez mental, sino en un clima de honesta franqueza” (p. 27).

Esbozamos a continuación los contenidos de las intervenciones de Girard, sirviéndonos de los mismos epígrafes de los subapartados en que se dividen, destacando algunos elementos de interesante carácter autobiográfico o que hacen mención a aspectos particulares.

Las exposiciones y comentarios de Girard se hallan transcritas y extractadas desde la página 50 a la página 84 , en la transcripción de fragmentos del diálogo, que abarca de la página 43 a la 93. En el apartado 1.6, titulado "René Girard 
(26.VI. 1990-tarde; intervención más larga)", dentro del subapartado 1.6.1, encontramos una serie de menciones a datos y episodios autobiográficos, donde destaca su valoración "de un catolicismo progresista y socialmente comprometido", con elogios a J. Maritain, E. Gilson y E. Mounier, aunque reconoce que solo fue más tarde, y no en su juventud, cuando fue consciente de su importancia. A su juicio, los únicos que escaparon de deslizarse en el fascismo o en el estalinismo fueron quienes estaban ligados a esta tradición católica. Reconoce que en su juventud se consideraba "ateo, izquierdista, pero generalmente apolítico" y que de los 10 a los 38 años no tuvo ningún contacto con la Iglesia (citado en Assmann, 1991, p. 51).

Girard confiesa sentirse en un ambiente que le permite hablar acerca de la vinculación entre su trabajo y su conversión al cristianismo (1.6.2, citado en Assmann, 1991, p. 52). Reconoce que algunos le atribuyen ideas preconcebidas equivocadas: los conservadores, presupuestos que no les agradan, y los progresistas, presupuestos de derechas. No obstante, dice intentar separar su intuición de sus opiniones circunstanciales. Se queja, además, de la actitud y la manera de citar selectiva con respecto a su trabajo, sobre todo en los medios universitarios (1.6.3 y 1.6.4, citado en Assmann, 1991, p. 52) y no sostiene que el ser humano sea tan solo deseo mimético o que se reduzca a este (citado en Assmann, 1991, p. 55).

El apartado 2.2 presenta una síntesis del circuito mimético y el 2.3 lleva por título "La especificidad del cristianismo en cuanto fermento evangélico" (Assmann, 1991, pp. 55-58). Los subapartados correspondientes al tercer día de diálogo, en los cuales hay transcripciones de las aportaciones de Girard, son el 3.1 y el 3.2. El 3.1 se refiere a la vinculación entre sacrificialismo e idolatría, ambos denunciados de forma conjunta en el Antiguo Testamento por los profetas, sostiene el pensador; el 3.2 trata acerca de qué son los mitos. Aquí Girard reacciona a una intervención anterior de Leonardo Boff, admitiendo que el deseo mimético no sirve para hablar de toda la experiencia humana, al tiempo que le pregunta si la armonía y la comunión de la que aquel habla es algo natural y capaz de resistir y oponerse al mundo y a las fuerzas generadoras de violencia, que a Girard le parecen más poderosas, algo sobre lo cual vuelven a discutir posteriormente (Assmann, 1991, pp. 58-63). El deseo mimético no sería solo ruin, sino que también, por ejemplo, habría contribuido a poner fin a las jerarquías feudales, o a elevar el nivel de vida, pero también al sufrimiento de los proletarios, acepta Girard (citado en Assmann, 1991, p. 69). 
La sección dedicada al cuarto día, a la sesión de finalización, recoge la intervención más extensa de Girard, invitado, según lo previsto en la programación del diálogo, a comentar y valorar las jornadas (Assmann, 1991, pp. 69-80). A esta le sigue, tras un resumen del comentario de Franz Hinkelammert, el resumen de la última manifestación de Girard, como reacción al anterior comentario ("4.2.2. René Girard [resumen]”, en Assmann, 1991, pp. 83-84). Esta parte, “4. Cuarto día: sesión de finalización”, se subdivide en quince subapartados de los que vamos a seleccionar algunas ideas e informaciones que pueden resultar de interés.

René Girard se confiesa "latino", en tanto que originario de la Francia meridional (le Midi), así como discriminado en el pasado por motivo de su acento en Francia. Se identifica con la sensibilidad latina de camaradería que vive en el diálogo con los teólogos en Brasil, compartiendo una verdadera fraternidad cristiana entre ellos. Dice de sí mismo tener un "temperamento efervescente y rebelde", que le hace que le repugne lo que llama "una jerga vacía sobre los pobres", presente en la clase intelectual del Primer Mundo, incluyendo universidades y medios católicos y que no afectaría a los teólogos de la liberación, capaces de ejercer la autocrítica, la libertad de lenguaje y apegados a la realidad, lejos de un nihilismo de textos sin relación con lo real ("4.1.1. Compañerismo placentero"; “4.1.2. Ausencia de una jerga”; “4.1.3. Libertad de lenguaje y sentido de la realidad”, citado en Assmann, 1991, pp. 70-71).

Girard no quiere que el deseo mimético y la teoría mimética se conviertan en ídolos, o se exagere su importancia, al tiempo que propone esta como herramienta en el rechazo del sacrificialismo, subrayando la ventaja de que esta conduciría de modo directo a una teoría de la redención que, a su juicio, es ortodoxa con todas las grandes iglesias cristianas. Asimismo, defiende la claridad de la teoría mimética y se declara impresionado por su utilidad en el plano pastoral. Define la teoría, antes que nada, como un instrumento de desmitificación, no totalmente incompatible con el análisis marxista y psicoanalítico, aunque se pretende más radical que ellos, y que sería respetuosa con la complejidad de lo real. Admira y comparte con los marxistas el respeto por la gran cultura occidental como búsqueda de la racionalidad y que algunos posmodernos pretenderían suprimir, y reivindica el análisis mimético como crítica literaria ("4.1.5. Algo sobre el deseo mimético”; “4.1.6. Incidencia en la teoría de la redención”; "4.1.7. Utilidad pastoral”; “4.1.8. Un instrumento de desmitificación”, citado en Assmann, 1991, pp. 72-74). 
En los últimos subapartados lo intelectual y lo autobiográfico siguen entremezclándose. Cuando identifica un sentido cristiano y un sentido pagano de la sabiduría, cita un encuentro suyo con Milan Kundera, quien le hablaba del deseo mimético como "la destilación de una determinada forma de sabiduría" "4.1.9. Análisis mimético y sabiduría”, citado en Assmann, 1991, p. 74). Girard propone encarar el deseo mimético como una especie de modificación moderna de la ascesis, considerando tanto el pecado individual como el social y, sobre todo, enfatiza que "todo el análisis del deseo mimético está al servicio de la conversión", no necesariamente cristiana, aunque el simbolismo cristiano se hallaría en las grandes novelas, en las que se muestra la renuncia a un tipo de yo individual, que no lo es (Moreno Fernández, 2014b). Girard se pregunta cómo hablar de la gracia sin dejar de lado una visión crítica de la realidad. Constata lo profundamente cristianos que serían los teólogos de la liberación, al tiempo que revolucionarios, proponiéndoles que no solo aporten su perspectiva, sino que comprendan la actitud quizás estrecha pero honesta de las autoridades eclesiásticas, reconociendo que también él es "mirado con extrema desconfianza por la ortodoxia". Cita, y comprende, una "cierta obsesión acerca del comunismo" por parte del papa Juan Pablo II, al tiempo que apela al mutuo entendimiento (“4.1.10. Deseo mimético y conversión”; “4.1.11. Ustedes son profundamente cristianos”; “4.1.12. ¿Cómo encarar los recelos acerca de la teología de la liberación?”, citado en Assmann, 1991, pp. 75-78).

A Girard le inquieta la "desaparición de los signos exteriores" en la teología de la liberación, al igual que a los "medios conservadores de la Iglesia". Propone entender y respetar las formas de religiosidad popular ya que, si no hubiese signos exteriores habría el riesgo de una disolución del cristianismo sin institución y solo pensado para individuos. Y, sin embargo, reconoce:

Somos fundamentalmente anti-ritualistas. Sé de esto muy bien porque, cuando retorné a la Iglesia Católica, experimenté un fuerte malestar en relación a los ritos y, de cierta manera, lo continúo sintiendo. Al mismo tiempo, pienso que ellos son necesarios (“4.1.13. No distanciarse de la religiosidad popular", citado en Assmann, 1991, pp. 78-79).

Aunque en el encuentro también apareció la vinculación del deseo mimético con los problemas económicos y sociales, y los sistemas de auto-regulación, 
Girard afirma que este terreno le resulta difícil y realiza una serie de comentarios aludiendo a Hinkelammert y Assmann. Advierte del riesgo del purismo no-sacrificial exagerado, que puede derivar en formas sacrificiales. Cree que ellos, más que los primeros cristianos, deben estar "más comprometidos en la política" y que la teología de la liberación "es fundamentalmente no violenta", aunque tiene razón al justificar ciertos modos de acción política, a pesar de que no sea la misma actitud de Pablo frente a los poderes de este mundo. Valora mucho la sabiduría de Pablo, así como su afán por no escandalizar a los hermanos ("4.1.14. Teoría mimética y sistemas auto-reguladores”, citado en Assmann, 1991, pp. 78-80).

5. Conclusión

Finalmente, el PENSADor dice haber EXPERIMENTAdo la apertura de los participantes en el diálogo y haber captado la teología de la liberación "más desde dentro". Califica el encuentro de extraordinario y espera que continúe algún día. Se disculpa por la posible arrogancia de hablar como si les diera consejos, vinculada a la espontaneidad y a la libertad surgidas entre ellos, y concluye: "[m]e siento muy feliz y muy agradecido" (“4.1.15. Nuestro diálogo debe proseguir”, citado en Assmann, 1991, p. 80). El resumen de contenido de su intervención, posterior a la de Hinkelammert, quien comenta la que antes ha tenido Girard, incide en los comentarios al teólogo sobre las lógicas sacrificiales, valorando y criticando la razón instrumental y proponiendo, a diferencia del cartesianismo, y al igual que Nietzsche y Heidegger, aunque de un modo distinto, escapar del sujeto trascendental y de la metafísica, pero pasando por las ciencias sociales (“4.2.2. René Girard [resumen]”, citado en Assmann, 1991, pp. 83-84).

Assmann confirma las impresiones de Girard cuando, además de describir el carácter de este como interlocutor abierto y muy afable, y hablar de su calidad humana, subraya la facilidad del diálogo y su comprensión de lo esencial y lo fundamental de la teología de la liberación. Frente a los superficiales, que harían de ella un panfleto, y también frente a los reduccionistas, que se quedarían solo con lo social o lo político, sería, afirma Assmann, un "movimiento de reflexión en medio de un movimiento real de fe junto con los pobres", con una "sustancia verdaderamente teológica”, sin la que no podría entenderse. A su juicio, el diálogo ha tratado lo esencial de esta teología: 
Para esta comprensión de lo que ella realmente es, hay, obviamente, algunos elementos relevantes. Primero, para que se nos entienda es necesario entender que somos efectivamente cristianos. Segundo, que somos cristianos comprometidos al lado de las mayorías oprimidas. Tercero, que somos gente razonablemente seria, y no unos improvisadores superficiales o meros repetidores de frases hechas. Estamos en constante búsqueda, autocrítica, revisión. No tenemos nada de dogmáticos. Y muy pocos entienden eso, a saber, nuestra discreta humildad, junto al coraje que tenemos de decir aquellas cosas que nuestra fe no nos permite silenciar (citado en Assmann, 1991, pp. 91-92).

Assmann (1991) expresa el agradecimiento de los teólogos a Girard por haberles entendido y respetado y, más allá de la convergencia de ideas, "por habernos reconocido con el mirar de la fe" (p. 93).

Concluimos con un fragmento, palabras del propio Girard (citado en Assmann, 1991) a través de las cuales les habla explícitamente a los teólogos de la liberación sobre su propia situación:

Pienso que lo que hay de desafiador en la situación latinoamericana es que ustedes son los primeros en vivir, en su carne, el peligro de la palabra sacrificio tal como es empleada usualmente. Ustedes viven en un estado de extraordinaria urgencia. Y esto forzosamente influye en sus actitudes. Ustedes llaman la atención del mundo sobre esta situación absolutamente intolerable. Lo esencial es inclinarse delante de eso y reconocer la situación.

Existe otra manera de sacrificar a las personas: la indiferencia. El deseo mimético de los indiferentes se concentra sobre un proyecto obsesivo y destruye la importancia de todo el resto. Pienso que en la cuestión de los pobres hay evidentemente sacrificios, pero para entenderlos es necesario reflexionar sobre esa indiferencia enfermiza. Son sacrificios en sentido derivado, imperceptible, en tanto derivados de esa indiferencia. Ustedes, en cuanto teólogos, son objeto de atención de algunos, no obstante, los pobres son objeto de un olvido terrible. Hoy los indiferentes parecen decir: a América Latina la dejamos abandonada a sí misma (p. 28).

Una denuncia girardiana, la del sacrificio ligado a la indiferencia, que recuerda hoy, un cuarto de siglo después, más allá de Latinoamérica, a la denuncia del papa Francisco de la "globalización de la indiferencia", que sigue generando 
incontables víctimas, con el tráfico de personas, las guerras y la insensibilidad de la cultura del bienestar como telón de fondo (Boo, 2013, p. 52). Esperamos haber contribuido a recuperar este episodio y esta publicación injustamente olvidados, de manera que no sean expulsados sino tenidos en cuenta para el estudio y la divulgación de la obra, el pensamiento y la biografía intelectual de René Girard en toda su amplitud.

\section{Referencias}

Assmann, H. (1991). Sobre ídolos y sacrificios: René Girard con teólogos de la liberación. San José, Costa Rica: DEI. [Edición original en portugués: Assmann, H. (1991). René Girard com teólogos da libertação: um diálogo sobre ídolos e sacrificios. Petrópolis, Piracicaba, Brasil: Editora Vozes / Editora UNIMEP)

Boo, J. V. (2013, octubre 4). La denuncia de la "globalización de la indiferencia". ABC de Sevilla, p. 52.

De Castro Rocha, J. C. (2014). Mimetic Theory and Latin America. Reception and Anticipations. Contagion, 21, 75-120.

Girard, R. (1996). Cuando empiecen a suceder estas cosas... Conversaciones con Migchel Treguer. Madrid: Encuentro.

Girard, R. (2000). Los orígenes de la cultura. Conversaciones con Pierpaolo Antonello y Joao Cezar de Castro. Madrid: Trotta.

Girard, R. (2001). Aquel por el que llega el escándalo. Madrid: Caparrós.

Girard, R. (2004). Les appartenances. En: D. Mazzú. (Dir.), Politiques de Caïn (pp. 19-33). Bilbao: Desclée de Brouwer.

Girard, R. (2007). De la violence à la divinité. Paris: Grasset.

Girard, R. (2008). Entretien avec René Girard. Philosophie magazine, 23, 59-60.

Girard, R. (2010). Préface. En : Oughourlian, J. M. Psychopolitique (pp. 7-13). Paris: François-Xavier de Guibert.

Moreno Fernández, A. (2013). La evaluación de la modernidad en la teoría mimética de René Girard. Granada: Ed. Universidad de Granada. Recuperado de http://digibug.ugr.es/bitstream/10481/26378/1/21778954.pdf

Moreno Fernández, A. (2014a). Ontogénesis humana y filosofía del sujeto en la teoría mimética de René Girard. Revista de Filosofía, 39(2), 147-168. 
Moreno Fernández, A. (2014b). La conversión en la teoría mimética de René Girard. Pensamiento, 70(263), 277-305.

René Girard. (2016, abril 27). En: Wikipedia, La enciclopedia libre. Recuperado de https://es.wikipedia.org/wiki/Ren\%C3\%A9_Girard

René Girard. (2016, abril 27). En: Wikipédia, l'encyclopédie libre. Recuperado de https://fr.wikipedia.org/wiki/Ren\%C3\%A9_Girard

René Girard. (2016, abril 27). En: Wikipedia, The Free Encyclopedia. Recuperado de https://en.wikipedia.org/wiki/Ren\%C3\%A9_Girard

René Girard. (2016, abril 27). En: Wikipédia, a enciclopédia livre. Recuperado de https://pt.wikipedia.org/wiki/Ren\%C3\%A9_Girard

René Girard. (2016, abril 27). En: Wikipedia, Die freie Enzyklopädie. Recuperado de https://de.wikipedia.org/wiki/Ren\%C3\%A9_Girard

Ruiz Lozano, P. (2005). Antropología y religión en René Girard. Granada: Facultad de Teología de Granada. 